\title{
Hereditary arterial and articular multiple calcification syndrome
}

INSERM

\section{Source}

INSERM. (1999). Orphanet: an online rare disease and orphan drug data base. Hereditary arterial and articular multiple calcification syndrome. ORPHA:289601

Hereditary arterial and articular multiple calcification syndrome is a very rare genetic vascular disease of autosomal recessive inheritance, described in less than 20 patients to date, characterized by adult-onset (as early as the second decade of life) isolated calcification of the arteries of the lower extremities (including the iliac, femoral, and tibial arteries) as well as the capsule joints of the fingers, wrists, ankles and feet, and that usually manifests with mild paresthesias of the lower extremities, intense joint pain and swelling, and early onset arthritis of affected joints. 